\title{
Importance of Production Environments When Applying Industry 4.0 to Production Logistics - A Multiple Case Study
}

\author{
Jo Wessel Strandhagen, Erlend Alfnes, Jan Ola Strandhagen, Natalia Swahn \\ Department of Production and Quality Engineering \\ Norwegian University of Science and Technology \\ Trondheim, Norway \\ \{jo.w.strandhagen, erlend.alfnes, ola.strandhagen, natalia.swahn\}@ ntnu.no
}

\begin{abstract}
Manufacturing companies are now on the move towards the fourth industrial revolution, Industry 4.0. It is driven by rapid technological developments and the need for industrial actors make oneself independent of high labor costs. Industry 4.0 concerns several aspects of industrial production, including production logistics. The purpose of this paper is to investigate what are the key elements of Industry 4.0 that are related to production logistics, and how the production environment influence the applicability of these elements. This is done through a multiple case study of four Norwegian manufacturing companies. The findings from the study indicate that the applicability of the elements of Industry 4.0 related to production logistics are dependent on the production environment.
\end{abstract}

Keywords-Industry 4.0; Production Logistics; Production Environment

\section{INTRODUCTION}

Manufacturing companies are now on the move towards the fourth industrial revolution, Industry 4.0. Originating from the German strategic initiative Industrie 4.0 [1], it is now on the agenda in several European countries and in the US and Asia. It is built around rapidly developing technologies and concepts, e.g. the Internet of Things (IoT), and is expected to lead to a paradigm shift in industrial production. To remain competitive, Norwegian manufacturers and manufacturers in other countries where labor costs are high should explore the concept of Industry 4.0 to enable exploitation of the specific benefits it can offer in terms of new solutions for production and logistics in industrial production.

According to [2] the fundamental goal of production logistics is to achieve the highest delivery capability and reliability at the lowest possible logistic and production costs. The importance of production logistics can be emphasized by its ability to provide a major source of competitive advantage [3]. It can give competitive advantage both in terms of a value advantage and a cost advantage by increasing efficiency and productivity [3].

Industry 4.0 will have implications for industrial processes and value creation [1], thus it includes several aspects relevant for production management and production logistics. Production Planning and Control (PPC) is the central logistic control mechanism [4], and the applicability of PPC methods differs between production environments [5]. The production environment is here considered as the set of variables that describes the market related, product related and production process related characteristic features of a company. This leads to the hypothesis that the applicability of production logistic elements of Industry 4.0 in a company is dependent on the company's production environment. If Industry 4.0 is to improve production logistics performance, there are reasons to believe that the production environment will have a major impact on what aspects of Industry 4.0 should be approached for a specific company and how these should be approached. Thus, this paper sets out to investigate the importance of production environments when applying Industry 4.0 to production logistics.

Two research questions have been formulated:

1) What are key elements of Industry 4.0 related to production logistics?

2) How are the applicability of these elements affected by the production environment?

The rest of the paper is structured as follows. Sections II, III and IV will cover the theoretical background of relevant topics. Further, the methodology used in conducting the case studies is presented in section $\mathrm{V}$. A presentation of the case companies and findings from the case studies are provided in section VI, followed by a discussion of the findings in section VII. Limitations and further research and conclusions are provided in sections VIII and IX, respectively.

\section{WHAT IS INDUSTRY 4.0}

Industry 4.0 can be described as an umbrella term, referring to a range of current concepts and touching several disciplines within industry [6]. The key drivers for this fourth industrial revolution can be divided in two aspects. The first is the combination of rapidly advancing technological developments of today, including Internet of Things (IoT), Internet of Services (IoS), Cyber-Physical Systems (CPS) smart objects and big data, which is expected to lead to a paradigm shift in industrial production [6]. This can be described as a technology push that enables significant advances for industry. The second aspect is the demand from industrial actors to make oneself independent of high labor costs by exploiting new technology. This leads to businesses seeking new ways of offering their products and services, and even new business models are expected to emerge 
[1]. Reference [7] provides the following definition of Industry 4.0:

"Industry 4.0 is a collective term for technologies and concepts of value chain organization. Within the modular structured Smart Factories of Industry 4.0, CPS monitor physical processes, create a virtual copy of the physical world, and make decentralized decisions. Over the IoT, CPS communicate and cooperate with each other and humans in real time. Via the IoS, both internal and cross-organizational services are offered and utilized by participants of the value chain."

\section{INDUSTRY 4.0 AND PRODUCTION LOGISTICS}

Through a literature study, three key elements of Industry 4.0 related to production logistics have been identified.

To enable the IoT and real-time control it is necessary to give unique identifications to products, components and parts, hence a key element is:

- Automatic identification (Auto ID) and real-time control.

"Automated identification involves the automated extraction of the identity of an object" [8]. By enabling accurate and timely information about a specific item to be stored, retrieved and communicated, this information can be used to assist in automated decision-making and control functions relevant to that item. Identification technology has been developing very fast, seeing significant drops in the price of tags, equipment and infrastructure [9]. Radio frequency identification (RFID) is a type of Auto ID technology where radio frequency communications is used to identify and track objects attached with RFID tags [10]. It is considered as an enabler of the IoT within the Industry 4.0 concept [7].

Auto ID and RFID technology have been used industrially for a long time [8]. Now, however, by using network technology together with Auto ID technology, one is able to network information about products in a supply chain, and within a production facility [11], enabling real-time control of production [12].

Vertical integration of the factory and its sub-systems is a main feature of Industry 4.0 concerning the single factory, thus a second key element related to production logistics is:

- Integration and utilization of IT systems through vertical integration.

Information systems like ERP and MES are commonly used in supporting production logistics task and activities. Vertical integration is one main feature of Industry 4.0 [1], thus a vertical integration from the shop floor, up through different subsystems and to the ERP system will give a holistic and integrated management of information, that can improve production logistics.

The integration of IT systems is necessary to fully achieve the potential benefits of Auto ID technology [12]. Real time control of production through a RFID enabled shop floor requires that the information from the identification of objects are transmitted to the higher level IT system, whether it is a MES system or an ERP system.
Integration of IT systems and digitalization of production in the context of production logistics will mean that the tasks required for PPC and directing the flow of materials through the factory is performed with the support of IT systems. This will first require that the required systems are implemented, henceforth that the systems are utilized. The complete integration for real-time production control will also require an Auto ID enabled shop floor, as presented in [12].

Further automation and robotization as well as emerging production technologies, can have great implications for future production processes, giving the third element:

- Automation and new production technology.

Automation can be considered one of the main trends and expected developments within the Industry 4.0 concept [13]. One aspect of automation relates to manufacturing equipment, which will be characterized by the application of highly automated machine tools and robots [13]. The increased automation and robotization required for Industry 4.0 will also give developments in how humans are integrated in the production activities. Reference [13] outline a development towards a production situation where robots and human workers are highly integrated and working collaboratively on joint tasks. Human-robot collaboration on the shop floor can be a measure for increasing technological support for operators in a production company. Moreover, automation and robotization will also be of relevance in other areas apart from the production processes. Transportation, line feeding and material handling within a facility can also be exposed for more automated and robotized solutions. One example is Automated Guided Vehicles for transporting material through a factory. Embracing such technological developments can greatly benefit the internal production logistics of a company.

Additive manufacturing technology as 3D printing can be an enabler of more individualized production, which has been identified as one of the research streams within Industry 4.0 [14]. Additive manufacturing method's benefits over conventional manufacturing methods include batch reduction feasibility and design customization [15], which are relevant within the scope of Industry 4.0. Especially, supply chains where production of spare parts is a key part of the business due to high-level aftersales service are expected to benefit from effective use of additive manufacturing technologies [16].

These three key elements are considered as key elements for applying Industry 4.0 in the context of the production logistics of manufacturing companies.

\section{IMPLICATIONS OF THE PRODUCTION ENVIRONMENT}

As defined by [17] the production environment, or manufacturing environment, is "the framework in which manufacturing strategy is developed and implemented". Commonly it refers to whether a company is make-to-stock (MTS), assemble-to-order (ATO), make-to-order (MTO) or engineer-to-order (ETO). Given this definition, a company's production environment is highly influential on how the company delivers its products to its customers. Moreover, the applicability of PPC methods differs between production environments [5]. There is no one-size fits all approach to PPC, thus the characteristic features describing the production 
environment must be considered when designing the PPC system [5]. Reference [5] argue that the fit of production planning and control methods is dependent on characteristic features related to product, market and production processes, which constitute the production environment, or planning environment.

\section{METHODOLOGY FOR CASE STUDIES}

To investigate how Industry 4.0 can improve production logistics, four case companies have been included in the study. The companies have been selected based on their stated goal of improving their internal flow of materials and general aim of improving their production logistics performance. Moreover, they represent a range of varieties of Norwegian manufacturing companies, where a key variable is their production environments. The data on the case companies were obtained through two main approaches:

- A mapping of each company's production environment using a mapping framework.

- A focus group survey.

The main information used for mapping the production environment stems from company visits with walk-arounds, workshops and meetings within the research project, which of the case companies are partners. The participants from the case companies in these meetings and workshops were mainly supply chain managers, production managers, and logistics managers. In addition, existing documentation of the case companies were made available for conducting the mapping. The framework for mapping production environments presented in [18] was then used to identify the characteristics of each case company.

To collect information from the case companies on their opinions and interpretations of Industry 4.0 and production logistics, a survey was made. It was designed by following the general guidelines from [19]. The survey was presented to the case companies in a workshop at NTNU May 10th 2016. The workshop participants included representatives from the four case companies, as well as researchers, professors and PhD's affiliated with one or more of the case companies through their research. Having been a part of the research project, all participants had insights in the case companies, and were able to contribute in answering the survey together with the case companies' representatives. This way of conducting a survey is similar to what is termed "Focus Groups" in [20]. Focus groups capitalizes on communication between research participants in order to generate data, by taking a form of group interview [20]. Reference [20] states that such a group process can aid in clarifying and exploring views that would be more difficult to access in a one to one interview. The focus group method is particularly relevant when the survey questions are open ended, and requires discussion to be answered [20].

The answering of the survey was organized by dividing the workshop participants into four groups, one for each case company. The representatives for the case companies were assigned to their respective group, while the other participants were randomly distributed among the groups. Each group was instructed to answer the survey jointly, where one answer was mutually agreed upon for each question. This to reflect the group's interpretation and opinion as a whole. However, it must be noted that the data obtained from this survey results in only one qualitative answer from each company.

\section{CASE STUDIES}

This section will introduce the four case companies as well as the key findings from the mapping, analysis and survey results.

\section{A. Brunvoll}

Brunvoll AS develops and produces thruster systems for maneuvering and propulsion of various types of advanced vessels. The company is responsible for the whole thruster system, and business operations include design, production, sales and service. Brunvoll operates in a global market, delivering thruster systems for the following types of vessels: Offshore Support Vessels, Shuttle Tankers, Seismic Vessels, Advanced Fishing Vessels, Live Fish Carriers, Cruise Ships, Mega Yachts and Naval Vessels.

By producing thruster systems for advanced vessels, the business is highly dependent on the shipbuilding industry, which the main customers represent. Shipbuilding is a typical engineerto-order industry [21], and this has implications on the production strategy and placement of the customer order decoupling point (CODP) for Brunvoll. Production is based on a combination of an ETO and MTO strategy, where customizations are allowed. This gives a high number of possible product variants; hence, the production is not very repetitive.

In addition to developing and producing new thruster systems, the after-sales market and service is an important part of the business for Brunvoll. This gives additional requirements in terms of e.g. spare parts production.

\section{1) Characteristic features of Brunvoll}

The characteristic features related to production logistics at Brunvoll are presented below.

- Production strategy and CODP placement is a combination of ETO and MTO.

- Products are customized to a high extent.

- With the given production strategy a high number of product variants are offered.

- The shop floor layout is a combination of a fixed-position layout and cell layout with a high material flow complexity

- The average throughput time varies from several weeks to several months depending on product complexity.

- The production strategy of ETO and MTO gives infrequent order repetition.

\section{2) Towards Industry 4.0 for Brunvoll}

Brunvoll consider Industry 4.0 to be a realistic goal. However, the company has not put significant effort into investigating possible opportunities of it. It is in general viewed as a slight opportunity for increasing competitiveness, though only improving production logistics to some extent. 
Implementing Auto ID is not expected to improve the flow efficiency in the factory significantly. However, it is stated that Auto ID can be a measure to increase integration with customers.

The use of additive manufacturing like 3D printing is highly relevant for Brunvoll as it is expected to be applicable to a large extent. Implementing such technology is also expected to contribute to reduced complexity related to production logistics to a large extent. Furthermore, the percentage of automated processes is expected to increase over the coming years.

Currently, Brunvoll has implemented an ERP system and a PLM system. Moreover, implementing a MES system is under consideration. The company believes that the current ITinfrastructure is well suited for a transition to Industry 4.0. Furthermore, more integrated IT solutions are expected to have major positive implications for the future production logistics of the company. The company also states that the current IT system is far from utilized to its potential when it comes to functionality. Development of tailored IT-systems suited for the company's IT-requirements has not been considered, but focus is aimed at increasing the utilization of the current IT-systems.

The most important focus areas related to production logistics for Brunvoll are improving the flow of materials, reducing throughput time and inventories of raw materials and finished goods. Improving the methods and principles for planning and controlling production is part of this focus. Increasing the use of IT and integrating IT solutions are also issues to some extent, while standardization of products and components is considered less important.

\section{B. Kleven}

Kleven Maritime AS includes the two shipyards Kleven shipyard and Myklebust shipyard, both located on the west coast of Norway. Shipbuilding at Kleven Maritime AS (from now Kleven) includes Platform supply vessels, Construction vessels, Seismic vessels, and Anchor-handling vessels.

Production at Kleven is characterized by ETO production. Ships are designed and engineered in close collaboration with the customer, allowing a very high degree of customization. Moreover, the production of ships requires a fixed position type layout, where workers and materials are brought to the ship in production.

Kleven focuses on modularization of products for achieving production efficiency. This means that ships are produced in modules, and then assembled in to complete ships. The intention of this is to improve process control, production control and quality, and to reduce production lead times.

\section{1) Characteristic features of Kleven}

The characteristic features related to production logistics at Kleven are presented below.

- Typical ETO production.

- Products are highly customized, hence product variety is very high.

- The BOM for products are very complex.

- The shop-floor layout is a fixed position layout.
- Throughput time is typically several months, up to 1-2 years.

- There is a high number of major operations.

- Due to products being highly customized, the order repetition is very low.

2) Towards Industry 4.0 for Kleven

The survey response from Kleven indicate that the company has no specific opinion whether Industry 4.0 is a realistic goal for the company or not, and the company is only to a small extent investigating the specific opportunities of it. It is seen as neither a threat nor a possibility for the company in the future. Although, if pursued, it is to some extent expected to improve the production logistics of the company.

Implementing Auto ID is not expected to improve the flow efficiency in production significantly. However, it is stated that Auto ID can be a measure to increase integration with suppliers.

New technology like 3D printing is not expected to be applied to any significant extent at Kleven. It is neither expected to contribute to any reduced complexity in production logistics. However, over the last years, effort has been put in to increasing the automation and robotization of production. For example are some welding operations that previously were performed manually outside Norway now performed by robots at Kleven's shipyards in Norway. This is an enabler for maintaining production in Norway.

Today, Kleven has implemented an ERP system. The current IT infrastructure is to some extent expected to be suited for transition to Industry 4.0. More integrated IT solutions are expected to have a great positive impact on the production logistics of the company. As of today, developing IT systems inhouse is not of any special interest. Moreover, Kleven does not have any specific focus on using more of the functionality of the installed ERP system.

The most important focus areas for improving the efficiency of internal logistics are standardizing products and components and reducing throughput times. Improving the flow of materials and applying better methods and principles for planning and control is somewhat important, while reducing work-in-process and inventories are not of any specific importance.

\section{Ekornes}

Ekornes is a furniture production company, based in Ikornnes on the west coast of Norway. They are positioned within the medium/high-end of furniture products, with the aim to be a leading actor and producer of branded goods within the home furniture industry, both in the national and international market. The company's most known product is the Stressless reclining chair, but additional products like sofas, coffee tables etc. are also a part of the product portfolio.

Ekornes has a strong focus on allowing customization of products, especially in terms of skin type and color of chairs. This gives a large number of possible product variants. To be able to deliver their products to customers efficiently, the company has employed a combination of MTO and ATO production strategy. The effect in reality is that finalization of products are done after customer orders have been received. 
When a customer order is received, with the specific customization in terms of skin type and color, the skin is cut and sewed before the chair is assembled. Production is organized in a functional shop floor layout, with different departments responsible for each of the main production stages.

\section{1) Characteristic features of Ekornes}

The characteristic features related to production logistics at Ekornes are presented below.

- Production strategy is a combination of MTO and ATO, as skin is produced based on actual customer orders. Final products are assembled after skin has been processed.

- Customer specifications are allowed in terms of skin type and color in addition to some minor adjustments.

- The possibility for skin customization gives a high product variety.

- Downstream of the CODP the production lead time is less than required delivery lead time from customers, allowing MTO and ATO production.

- The shop floor layout is a functional layout with departments for each main production stage.

- Lead time from receipt of customer order to delivery is a few days.

\section{2) Towards Industry 4.0 for Ekornes}

Ekornes' survey response indicate that Industry 4.0 is a realistic goal and an opportunity for the company, but they have today only to a certain extent investigated the possibilities and opportunities of it. It is stated that Industry 4.0 on a general basis will improve the production logistics in the company to a large extent.

The applicability of Auto ID technology like RFID in the production at Ekornes is considered to be high. However, the company states that implementation of Auto ID for product track and trace is believed to give only a certain improvement in the flow efficiency of goods and material.

Production technologies such as 3D printing is not expected to have any impact on the production logistics of Ekornes. On the other hand, further automation of production processes is expected to be the case for the coming years.

Ekornes has today an ERP and MES system installed. Although projects have been initiated to investigate the possibilities for implementing both APS and PLM systems. Furthermore, the current IT-structure is not believed to be well suited for transition to Industry 4.0. More integrated IT-systems can improve the production logistics to a large extent. In addition, there are functionalities of the current IT systems that are not utilized. New/Tailored IT-systems suited for the company's IT-requirements is stated to be of relevance for Ekornes. On the other hand, today the company has no specific focus related to increasing the IT system utilization.

Improving the efficiency of material flow is a major focus area of Ekornes. Mainly this is to be achieved by reduced throughput times and increasing IT utilization.

\section{Pipelife}

Pipelife Norge AS is a part of the international Pipelife group. The group is headquartered in Austria, and is one of Europe's leading producers of plastic pipes. Pipelife Norge AS (from now Pipelife) is the Norwegian division of the group and produces plastic pipes for use in various areas, including water supply and sewage, heating ventilation and sanitation, cable protection, wiring and gas pipes.

Pipelife has a MTS production strategy, with highly standardized and repetitive production of pipes in large quantities. Customers are served from the inventory of finished goods. The company aims for cost advantage through economies of scale in their mass production of plastic pipes, and production is organized in a highly automated product line shop floor layout.

\section{1) Characteristic features of Pipelife}

The characteristic features related to production logistics at Pipelife are presented below.

- Pipelife has a typical MTS production strategy, with the CODP placed at the finished goods inventory.

- No customization is allowed, and products are picked and shipped from the finished goods inventory.

- The product variety and product complexity is very low, with only 1-2 levels in the BOM.

- Demand information is based on forecasts and stock replenishment orders when the level of finished goods reaches a certain level.

- Production is characterized as mass production in a product line shop floor layout, where production is highly repetitive.

- Changeover times and set-up times are major factors in the production process.

- Production is streamlined, with a low material flow complexity.

\section{2) Towards Industry 4.0 for Pipelife}

Pipelife's response on the survey indicates that the company sees Industry 4.0 as a very realistic goal, and is to a large extent investigating possible opportunities. Furthermore, it is generally viewed as a great opportunity for the company, and is expected to improve production logistics to a large extent. Specifically, an implementation of Auto ID is expected to be highly applicable for Pipelife, and it is expected to give significant improvements to production logistics.

Production technologies such as 3D printing is not considered relevant for Pipelife. On the other hand, a large amount of the production processes are automated, and this amount is expected to increase over the next years.

Pipelife has today implemented an ERP system and a MES system, and the current IT infrastructure is expected to be suited for transition to Industry 4.0 to a large extent. Pipelife also states that more integrated IT solutions will have a positive impact on the production logistics of the company. Developing new tailored IT systems are not of any special interest. On the other 
hand, Pipelife has to a large extent a focus on increasing the current IT utilization to apply more of the available functionality.

To achieve more efficient internal logistics, improving the flow of materials and increasing IT-utilization are the primary focus areas of Pipelife, together with reducing changeover times. Finding better methods and principles for planning and control and reducing inventories of raw materials and finished goods are also of a certain importance. Standardization of components, increasing flexibility and reducing work-in-process are less important focus areas.

\section{DISCUSSION OF CASE STUDY FINDINGS}

The mapping and analysis of the production environment characteristics of the case companies indicate that the applicability of production logistics related elements of Industry 4.0 varies with these characteristics. The differences in production environments call for different approaches to Industry 4.0. A general roadmap or set of guidelines for Industry 4.0 that is applicable for all companies have not been identified in this study.

As indicated in [11] and [22] the shop floor layout is an important source of creating complexity in a production environment. Especially, in a fixed-position layout and a functional layout the material flows are not unidirectional. Shipbuilding is characterized by a fixed position layout, where materials, workers and production equipment have to be brought to the product being processed. In such a setting, monitoring and data collection of what is happening can be difficult and implementing real time control to any extent can be more problematic than with layouts where the material flow is less complex.

High product varieties can give implications for implementing Auto ID. It is expected that uniquely identifying a high number of product variants produced in low volumes is more difficult than uniquely identifying a low number of variants produced in high volumes. Auto ID is considered as a key enabler for real time monitoring and control, which consequently can be difficult to implement for a company where product variety is high.

Generally, characteristics of the production environment that increases the complexity is expected to reduce, or at least imply on, the applicability of implementing key elements of Industry 4.0. Thus, analyzing the production environment is a prerequisite before Industry 4.0 can be applied to production logistics.

Although the sample analyzed only contains four companies, the results from the mapping and survey indicate that there is a relation between the repetitiveness of production, CODP placement and the companies' perceived Industry 4.0 applicability.

Of the four case companies, Pipelife, with their production line layout and MTS strategy, has the highest level of production repetitiveness. Pipelife is also the company that sees the highest potential for approaching and benefitting from Industry 4.0 and are most active in pursuing it. They see very high potential benefits from implementing Auto ID to improve production logistics. In comparison, Ekornes and Brunvoll have lower levels of production repetitiveness, and ATO/MTO and MTO/ETO strategies, respectively. These two companies state the potential benefits of Industry 4.0 to be medium/high, and are not exploring the specific possibilities of Industry 4.0 in the same way as Pipelife. Lastly, Kleven is the most ETO-oriented company of the four, with the lowest level of production repetitiveness. Moreover, Kleven see less potential benefits from Industry 4.0 than the other companies in this study, and has the longest way to go to reach an Industry 4.0 level of production.

\section{VIII.LIMITATIONS AND FURTHER RESEARCH}

Conducting a study on more than one case company limits the level of detail of the mapping and analysis of the case companies. This is a limitation to the study. Moreover, with a scope aiming at production logistics, several of the aspects related to Industry 4.0, which may be of high relevance for the case companies, have been neglected.

Further research should include more detailed investigations of how the technological advances related to Industry 4.0 can be employed in production logistics. A more detailed exploration of the company specific suggestions for approaching Industry 4.0. Moreover, a similar study can be conducted with other case companies.

\section{CONCLUSIONS}

A general roadmap or set of guidelines for moving towards Industry 4.0 has not been identified in this study. Moreover, the findings from the case studies and analysis of the survey suggest that a roadmap for Industry 4.0 will be dependent on the characteristics of each specific company. Especially, the facility layout, the product variety, and the BOM and product structure complexity will have implications on Industry 4.0 applicability in the context of production logistics. Hence, there is no "onesize fits all" approach when it comes to Industry 4.0. A company specific or industry specific approach seems necessary to reap the potential opportunities and benefits from Industry 4.0.

The sample of case companies investigated in this study indicate that companies with low degree of production repetitiveness, high material flow complexity and high degree of ETO production are least suited for a transition to Industry 4.0 in terms of production logistics. Companies with a higher degree of production repetitiveness, lower material flow complexity and lower degree of ETO production are in comparison less challenged by the production environment. Moreover, they are more actively investigating the possibilities Industry 4.0 technologies can offer.

\section{ACKNOWLEDGMENT}

The authors would like to acknowledge the support from the ongoing research project Manufacturing Network 4.0 and its partners, for supporting the research presented in this paper. Moreover, the authors would like to thank the representatives of the case companies for their contribution to the data acquisition process and their support of the research. 


\section{REFERENCES}

[1] H. Kagermann, J. Helbig, A. Hellinger, and W. Wahlster, Recommendations for Implementing the Strategic Initiative INDUSTRIE 4.0: Securing the Future of German Manufacturing Industry; Final Report of the Industrie 4.0 Working Group: Forschungsunion, 2013.

[2] P. Nyhuis and H.-P. Wiendahl, Fundamentals of production logistics: theory, tools and applications: Springer Science \& Business Media, 2008.

[3] M. Christopher, Logistics and supply chain management: creating valueadded networks: Pearson education, 2005.

[4] H. H. Wiendahl, G. Von Cieminski, and H. P. Wiendahl, "Stumbling blocks of PPC: Towards the holistic configuration of PPC systems," Production Planning \& Control, vol. 16, pp. 634-651, 2005.

[5] P. Jonsson and S.-A. Mattsson, "The implications of fit between planning environments and manufacturing planning and control methods," International Journal of Operations \& Production Management, vol. 23, pp. 872-900, 2003.

[6] H. Lasi, P. Fettke, H.-G. Kemper, T. Feld, and M. Hoffmann, "Industry 4.0," Business \& Information Systems Engineering, vol. 6, p. 239, 2014.

[7] M. Hermann, T. Pentek, and B. Otto, "Design principles for Industrie 4.0 scenarios: a literature review," Technische Universität Dortmund, Dortmund, 2015.

[8] D. McFarlane, S. Sarma, J. L. Chirn, C. Wong, and K. Ashton, "Auto ID systems and intelligent manufacturing control," Engineering Applications of Artificial Intelligence, vol. 16, pp. 365-376, 2003.

[9] E. Ilie-Zudor, Z. Kemény, F. van Blommestein, L. Monostori, and A. van der Meulen, "A survey of applications and requirements of unique identification systems and RFID techniques," Computers in Industry, vol. 62, pp. 227-252, 2011.

[10] Y. Xiao, S. Yu, K. Wu, Q. Ni, C. Janecek, and J. Nordstad, "Radio frequency identification: technologies, applications, and research issues," Wireless Communications and Mobile Computing, vol. 7, pp. 457-472, 2007.

[11] N. Slack, S. Chambers, and R. Johnston, Operations management: Pearson education, 2010.
[12] E. Arica and D. J. Powell, "A Framework for Real Time Production Planning and Control," in International Workshop of Advanced Manufacturing and Automation, 2013.

[13] T. Stock and G. Seliger, "Opportunities of Sustainable Manufacturing in Industry 4.0," Procedia CIRP, vol. 40, pp. 536-541, 2016.

[14] M. Brettel, N. Friederichsen, M. Keller, and M. Rosenberg, "How virtualization, decentralization and network building change the manufacturing landscape: An Industry 4.0 Perspective," International Journal of Mechanical, Industrial Science and Engineering, vol. 8, pp. 3744, 2014.

[15] J. Holmström, J. Partanen, J. Tuomi, and M. Walter, "Rapid manufacturing in the spare parts supply chain: alternative approaches to capacity deployment," Journal of Manufacturing Technology Management, vol. 21, pp. 687-697, 2010.

[16] S. H. Khajavi, J. Partanen, and J. Holmström, "Additive manufacturing in the spare parts supply chain," Computers in industry, vol. 65, pp. 50-63, 2014.

[17] APICS. Online Dictionary. Available: http://www.apics.org/gsa-mainsearch

[18] S.-V. Buer, J. W. Strandhagen, J. O. Strandhagen, and E. Alfnes, "Frameworks for Strategic Fit of Planning Environments. A Case Based Exploratory Study," 2016.

[19] C. Forza, "Survey research in operations management: a process-based perspective," International journal of operations \& production management, vol. 22, pp. 152-194, 2002.

[20] J. Kitzinger, "Qualitative research. Introducing focus groups," BMJ: British medical journal, vol. 311, p. 299, 1995.

[21] J. Gosling and M. M. Naim, "Engineer-to-order supply chain management: A literature review and research agenda," International Journal of Production Economics, vol. 122, pp. 741-754, 2009.

[22] B. L. MacCarthy and F. C. F. Fernandes, "A multi-dimensional classification of production systems for the design and selection of production planning and control systems," Production Planning \& Control, vol. 11, pp. 481-496, 2000. 